\title{
Publication of a Special Issue: Robotic Surgery in Urology
}

\author{
Claire Redhead \\ TheScientificWorld, Ltd., UK
}

Published September 19, 2006

TheScientificWorldJOURNAL and TSW Urology are pleased to have published the special issue 'Robotic Surgery in Urology', a collection of peer-reviewed papers on a range of key topics in this field. Organized by Dr. William Steers (Hovey Dabney Professor and Chair, Department of Urology, University of Virginia School of Medicine), this special issue explores the rapidly escalating use of robotics in urological surgery and features papers on ranging from the economics and logistics of setting up a program to the technical details of robotic prostatectomy, cystectomy, pyeloplasty, and other pelvic surgeries.

Specific topics covered are:

- Pediatric Robotic-assisted Laparoscopy: A Description of the Principle Procedures

- Tips on Establishing a Robotics Program in an Academic Setting

- Update on Robotic Laparoscopic Radical Prostatectomy

- Robotic Assisted Prostatectomy: A review of Vattikuti Institute Prostatectomy (VIP). 1500 cases.

- Robot-assisted radical cystectomy in the management of bladder cancer

- Future directions of robotic surgery: Case study of athermal robotic technique of prostatectomy.

- Histopathologic outcomes of robotic radical prostatectomy

The Publisher wishes to thank the authors and reviewers, and especially acknowledges the contribution of Dr. Steers in bringing about the publication of this special issue.

\footnotetext{
This article should be cited as follows:

Redhead, C. (2006) Publication of special issue: robotics surgery in urology. TSW Urology 1(S1), 73. DOI 10.1100/tswurol.2006.91.
} 


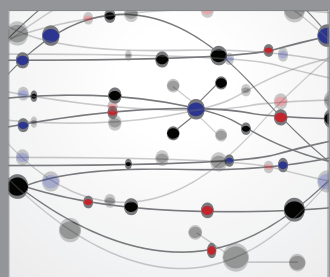

The Scientific World Journal
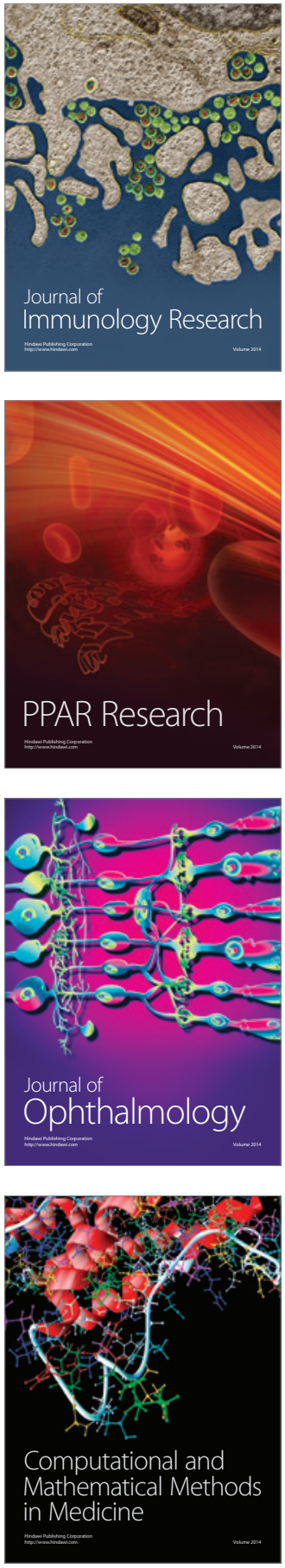

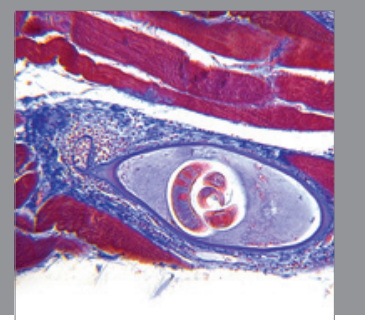

Gastroenterology

Research and Practice
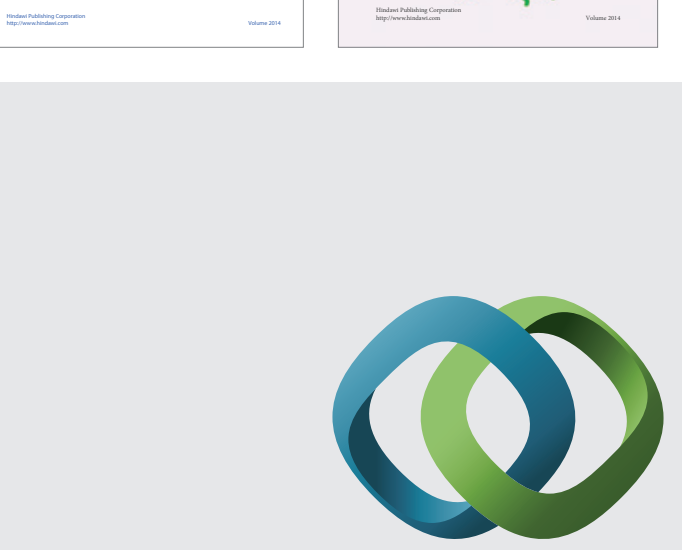

\section{Hindawi}

Submit your manuscripts at

http://www.hindawi.com
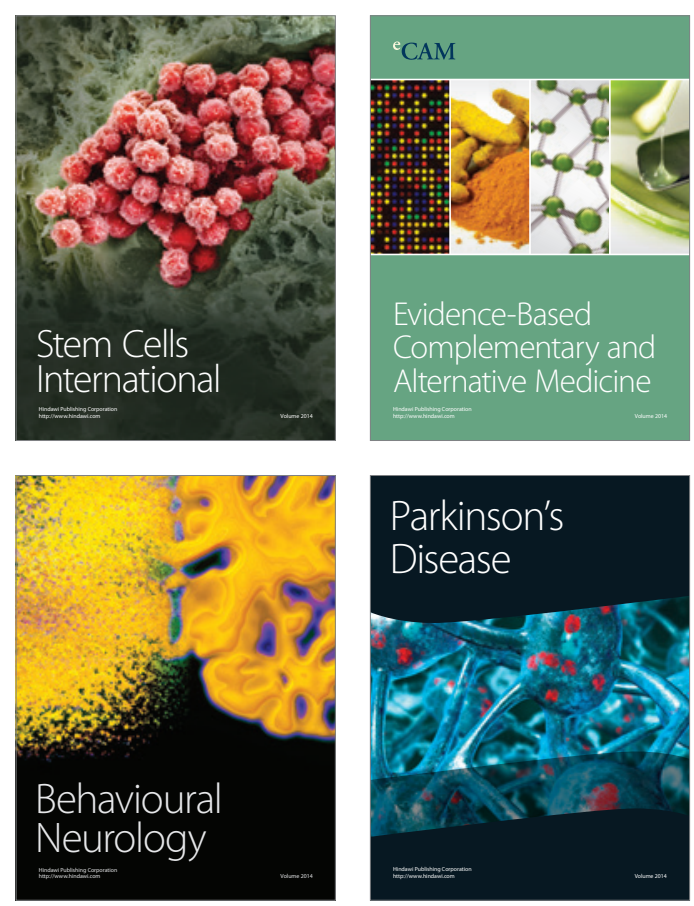

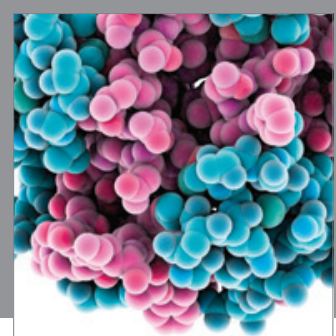

Journal of
Diabetes Research

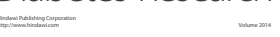

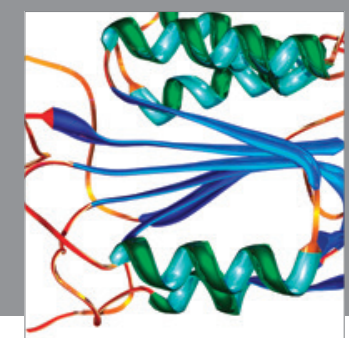

Disease Markers
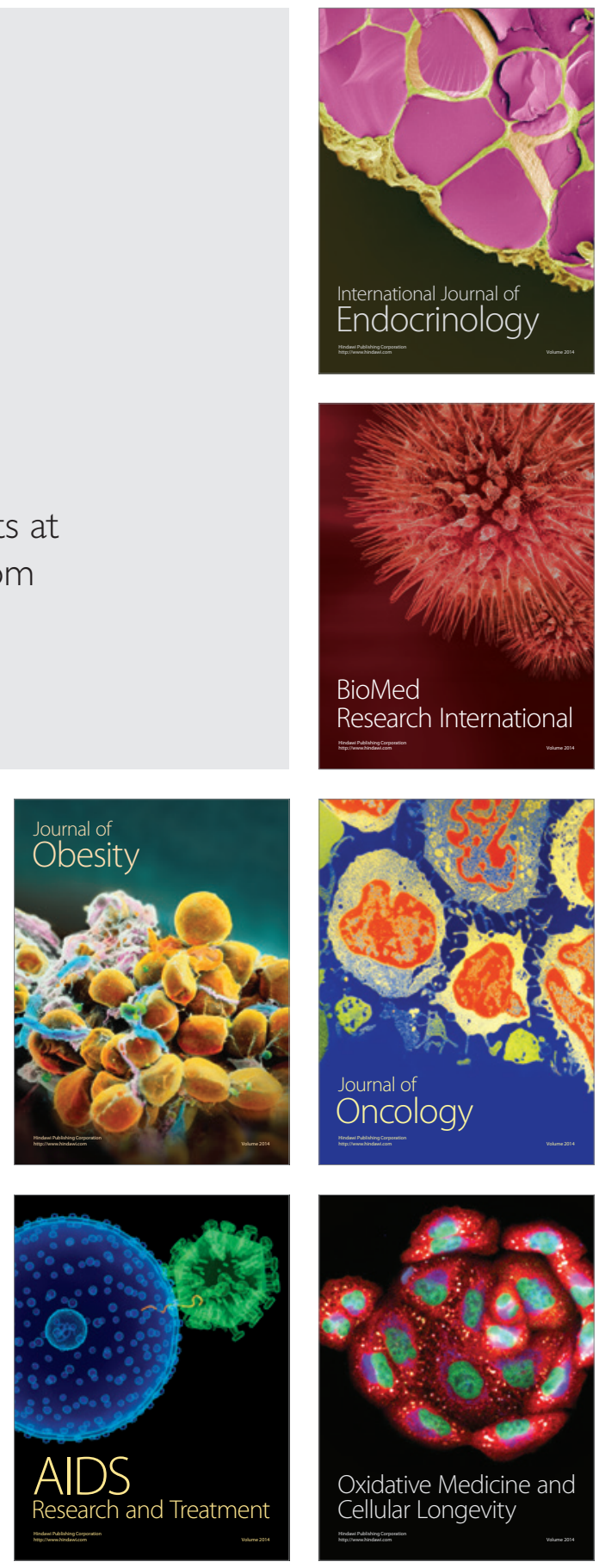